\title{
Plasmin Activation of Glial Cells through Protease-Activated Receptor 1
}

\author{
André R. Greenidge, ${ }^{1}$ Kiana R. Hall, ${ }^{1}$ Ian R. Hambleton, ${ }^{1}$ Richelle Thomas, ${ }^{1}$ \\ Dougald M. Monroe, ${ }^{2}$ and R. Clive Landis ${ }^{1}$ \\ ${ }^{1}$ Edmund Cohen Laboratory For Vascular Research, Chronic Disease Research Centre, University of the West Indies, \\ Cave Hill, Barbados \\ ${ }^{2}$ Division of Hematology/Oncology, School of Medicine, University of North Carolina, Chapel Hill, NC, USA
}

Correspondence should be addressed to R. Clive Landis; clive.landis@cavehill.uwi.edu

Received 23 April 2012; Accepted 7 December 2012

Academic Editor: Piero Tosi

Copyright (C) 2013 André R. Greenidge et al. This is an open access article distributed under the Creative Commons Attribution License, which permits unrestricted use, distribution, and reproduction in any medium, provided the original work is properly cited.

\begin{abstract}
The objective of this study was to determine whether plasmin could induce morphological changes in human glial cells via PAR1. Human glioblastoma A172 cells were cultured in the presence of plasmin or the PAR1 specific activating hexapeptide, SFLLRN. Cells were monitored by flow cytometry to detect proteolytic activation of PAR1 receptor. Morphological changes were recorded by photomicroscopy and apoptosis was measured by annexinV staining. Plasmin cleaved the PAR1 receptor on glial cells at 5 minutes $(P=0.02)$. After 30 minutes, cellular processes had begun to retract from the basal substratum and by 4 hours glial cells had become detached. Similar results were obtained by generating plasmin de novo from plasminogen. Morphological transformation was blocked by plasmin inhibitors aprotinin or epsilon-aminocaproic acid $(P=0.03)$. Cell viability was unimpaired during early morphological changes, but by 24 hours following plasmin treatment $22 \%$ of glial cells were apoptotic. PAR1 activating peptide SFLLRN (but not inactive isomer FSLLRN) promoted analogous glial cell detachment $(P=0.03)$, proving the role for PAR1 in this process. This study has identified a plasmin/PAR1 axis of glial cell activation, linked to changes in glial cell morophology. This adds to our understanding of pathophysiological disease mechanisms of plasmin and the plasminogen system in neuroinjury.
\end{abstract}

\section{Introduction}

Plasmin is a serine protease best known for its thrombolytic properties in the coagulation system. However, it can also act on cells that bear receptors belonging to the protease-activated receptor (PAR) family to cause secretion of inflammatory cytokines, oxidative radicals, matrix metalloproteinases, proliferation, cell migration, and platelet aggregation [1-6]. PARs are widely expressed in the central nervous system [7].

Plasmin is generated from plasminogen, by proteolytic cleavage with either tissue-type plasminogen activator (tPA), urinary plasminogen activator (uPA), or bacterial streptokinase. It catalyzes the breakdown of fibrin into D-dimers, hence acting as a brake on coagulation. Antifibrinolytics are in clinical use to limit bleeding in cardiac surgery and intracranial bleeding in traumatic brain injury $[8,9]$.
Antifibrinolytics fall into two categories: lysine analogues that prevent plasmin generation from plasminogen, (e.g., $\varepsilon$-aminocaproic acid), or active site inhibitors (e.g., serine protease inhibitor aprotinin [10]).

A pathophysiological role has been recognized for the plasminogen-activating system in exacerbating intracranial bleeding, excitotoxicity and cell death in neurons or white matter, ischemia reperfusion injury, and increased permeability of the blood-brain barrier (BBB) [11-17]. Alterations in BBB permeability were accompanied by profound changes in cell shape to astroglial cell lines or primary glial cells, via an incompletely understood receptor mechanism [15]. This phenomenon has been confirmed in cardiac surgery patients with clinical evidence for glial cell injury [18].

PAR receptors share a common activation mechanism, whereby proteolytic cleavage unmasks a hexapeptide ligand sequence in the exodomain of the receptor, which can 


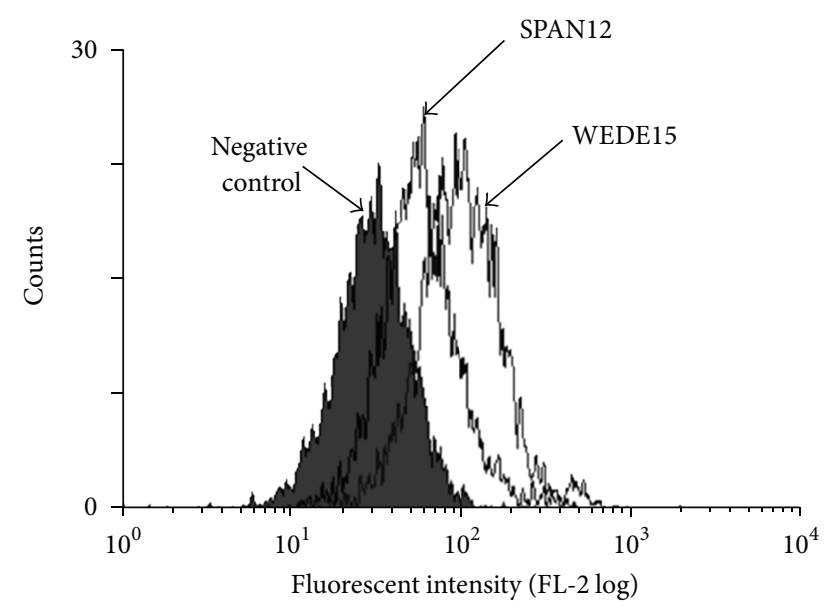

FIGURE 1: Expression of PAR1 epitopes. Flow cytometric histogram depicting expression of WEDE15 (a pan-receptor antibody) and SPAN12 (an activation-dependent antibody) on human A172 glioma cells. The filled histogram represents background staining with control antibody of the same isotype $\left(\operatorname{IgG}_{1}\right)$.

then dock intramolecularly and transmit G-protein-coupled signals into the cell [19]. PAR1 is activated by any serine protease that cuts specifically at arginine ${ }^{41}$-serine ${ }^{42}$ of the receptor generating the hexapeptide serine ${ }^{42}$-phenylalanineleucine-leucine-arginine-asparagine ${ }^{47}$ (SFLLRN) at the new $\mathrm{N}$-terminus. PAR1 activating proteases include thrombin, plasmin, and trypsin [20-22].

Although plasmin and PAR1 have independently been implicated in pathways of cerebral injury, a plasmin/PAR1 axis remains to be identified in cells of the central nervous system. In mice, genetic deletion of the PAR1 homolog or deletion of tPA confers neuroprotection in a model of transient cerebral ischemia [16, 22, 23]. Although plasmin has not been studied in this context, other PAR1 agonists trigger excitotoxicity, cell invasion, and apoptosis in neurons, astrocytes, and microglia [13, 16, 22, 24-28]. Hence, we investigated the ability of plasmin to activate central nervous system glial cells via PAR1 in an effort to identify key cellular events and highlight potential therapeutic targets.

\section{Methods}

2.1. Materials. Plasmin, plasminogen, streptokinase, aprotinin, and $\varepsilon$-aminocaproic acid were purchased from SigmaAldrich (St. Louis, MO). Phycoerythrin (PE) conjugated antibodies WEDE15(PE) and SPAN12(PE) were purchased from Beckman-Coulter (Caguas, PR). Phycoerythrin conjugated control antibody of the same isotype (IgG1-PE) was also purchased from Beckman-Coulter. PAR1 receptor activating hexapeptide (SFLLRN) and inactive scramble peptide (FSLLRN) were generated in house (University of North Carolina, Chapel Hill, NC) using an Applied Biosystems 432A Peptide Synthesizer (Life Technologies Corporation, Foster City, CA) and purified by reverse phase HPLC.

2.2. Cell Culture. The human glioma cell line A172 was purchased from the American Type Culture Collection
(ATCC; Manassas, VA). Cells were maintained in Dulbecco's Modified Eagle's Medium (DMEM) enriched with $10 \%$ fetal calf serum, $2 \mathrm{mmoles} / \mathrm{L}$ L-glutamine, $100 \mathrm{U} / \mathrm{mL}$ penicillin, and $100 \mu \mathrm{g} / \mathrm{mL}$ streptomycin (all Sigma-Aldrich) at $37^{\circ} \mathrm{C}$ in a humidified environment with $5 \% \mathrm{CO}_{2}$. At confluence cells were detached using cell dissociation medium (Sigma Aldrich), a trypsin-free detachment step that avoids possible PAR1 activation by trypsin [20, 29]. For plasmin activation, cells were cultured to confluence in Corning Costar 24well tissue culture plates (Sigma-Aldrich). Purified plasmin (Sigma-Aldrich) was used at $5 \mathrm{U} / \mathrm{mL}$. Plasmin was also generated in situ from plasminogen and streptokinase (SigmaAldrich), monitoring plasmin generation spectrophotometrically with Spectrozyme colour reagent (American Diagnostica, Stanford, CT) at $405 \mathrm{~nm}$ using a Multimode Detector (Dynex Technologies, Chantilly, VA). Where indicated, aprotinin was used at $200 \mathrm{KIU} / \mathrm{mL}$ and $\varepsilon$-aminocaproic acid at 10 mmoles/L. SFLLRN or FSLLRN peptides were used at a concentration of $25 \mu \mathrm{moles} / \mathrm{L}$.

2.3. PAR1 Expression and Cleavage. PAR1 receptor expression and cleavage was carried out by flow cytometry as previously described [29]. Briefly, total receptor expression was assessed using the pan-reactive anti-PAR1 antibody WEDE15, whereas receptor activation due to plasmin cleavage was monitored using antibody SPAN12. SPAN12 detects only the intact (i.e., unactivated) PAR1 receptor; therefore, loss of SPAN12 staining provides a linear measure of receptor activation [30]. Staining was carried out on freshly passaged cells in suspension following stimulation with plasmin for 5 minutes at $37^{\circ} \mathrm{C}$. Staining with WEDE15, SPAN12, or classmatched $\left(\operatorname{IgG}_{1}\right)$ control antibody was carried out at $20 \mu \mathrm{g} / \mathrm{mL}$ for 15 minutes on ice, followed by three washes in icecold PBS. Flow cytometric analysis was performed using an EPICS XL flow cytometer (Beckman Coulter). WEDE15 or SPAN12 staining was expressed in units of relative fluorescent intensity (RFI), a ratio of the mean fluorescent staining intensity obtained with detection antibody versus the staining intensity of a class-matched control antibody (i.e., an RFI of 1.00 is equivalent to no detectable expression). Results were expressed as median \pm IQR (RFI units).

2.4. Morphological Changes. Cells were observed and photographed at $0 \mathrm{~min}, 30 \mathrm{~min}, 4 \mathrm{~h}$, and $24 \mathrm{~h}$ using a Leica DM IL inverted microscope (Leica Microsystems, Wetzlar, Germany) at $\times 40$ or $\times 100$ magnification. Morphological changes were scored on a 6-point ordinal scale according to the scheme: 1 = fully confluent lawn of cells; 2 = cellular pseudopodia have started to retract from one area; $3=$ cell processes has started to retract from multiple areas; 4 = cell lawns show visible detachment from well substrata and flapping; 5 = cells have completely detached from well substrata to form a floating island; $6=$ floating island of cells with shrivelled appearance.

2.5. Apoptosis. Apoptosis of A172 cells was monitored flow cytometrically by staining with Annexin V FITC Apoptosis Detection Kit according to the manufacturer's instructions (Sigma-Aldrich). The percentage of apoptosis was calculated 


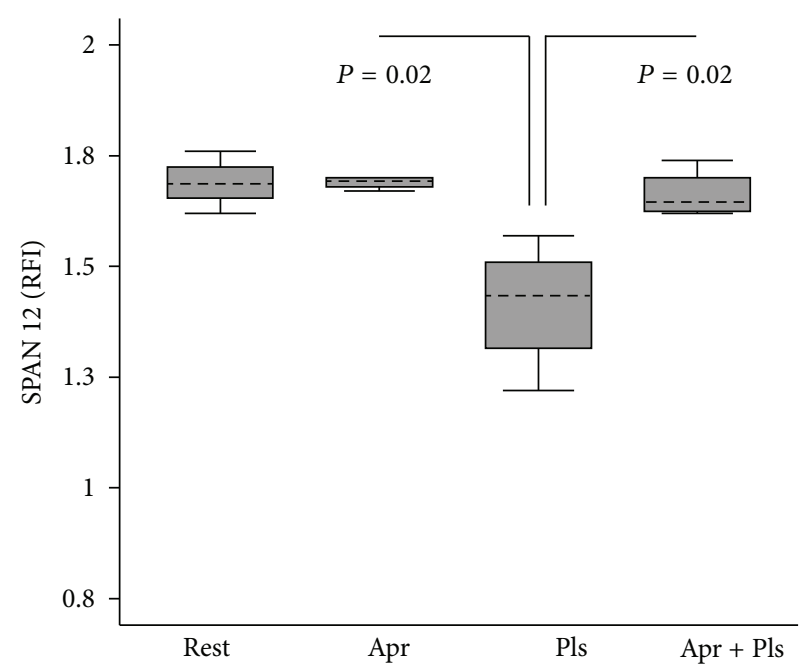

(a)

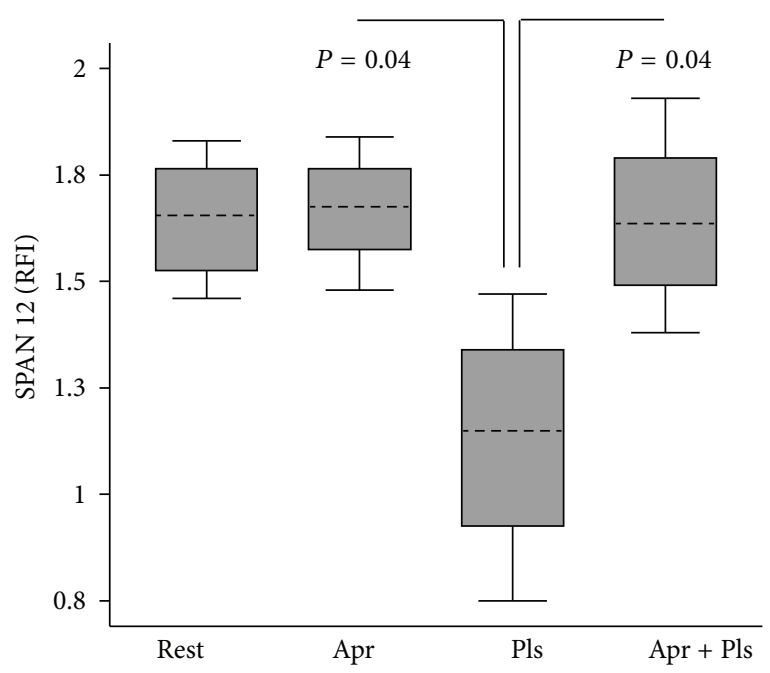

(b)

FIGURE 2: Effect of plasmin on PAR1 receptor activation. Proteolytic activation of PAR1 at 5 minutes was monitored flow cytometrically using antibody SPAN12 to detect intact (i.e., unactivated) receptor. Results were expressed in units of relative fluorescent intensity (RFI), calculated by dividing the mean fluorescent staining intensity obtained with SPAN12 antibody by the staining intensity obtained with a class matched $\left(\mathrm{IgG}_{1}\right)$ control antibody. Results were expressed as the median \pm interquartile range (IQR) from $n=4$ experiments. (a) Preformed plasmin $(5 \mathrm{U} / \mathrm{mL})$. (b) Plasmin generated in situ from plasminogen. Rest = resting; Pls = plasmin; Apr = aprotinin $200 \mathrm{KIU} / \mathrm{mL}$.
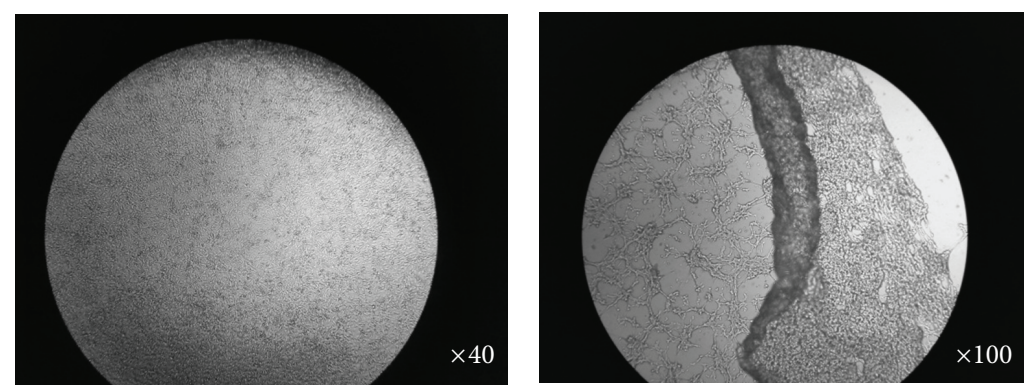

(a)

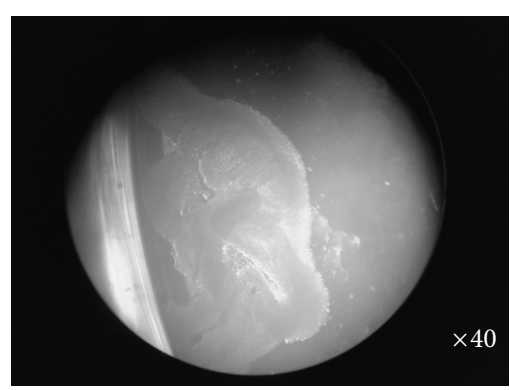

(d) (b)

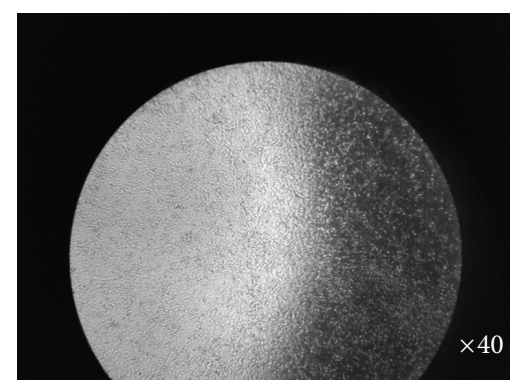

(e)

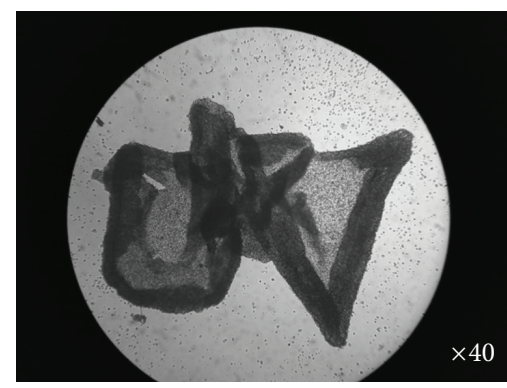

(c)

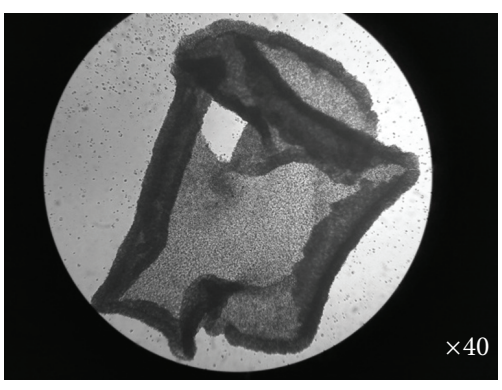

(f)

Figure 3: Effect of plasmin on cell morphology. (a) Time 0: confluent lawn of resting A172 glial cells. (b) 30 minutes after addition of plasmin: cell processes have started retracting from basal substrata, and flaps of detached cells were observed, although cell-to-cell contacts were maintained. (c) 4 hours: A172 cells fully detached into a floating island. (d) 24 hours: shrivelled floating cell mass. (e) 24 hours: aprotinin $(200 \mathrm{KIU} / \mathrm{mL})$ preserved the confluent monolayer of A172 cells in the face of plasmin activation. (f) 24 hours: a PAR1 agonist peptide SFLLRN $(25 \mu \mathrm{moles} / \mathrm{L})$ triggered analogous glial cell detachment as observed for plasmin in (d). Control peptide FSLLRN did not trigger any morphological changes (not shown). The magnification is indicated at the bottom right of each panel. Representative photomicrographs from $n=3-5$ experiments are shown. 


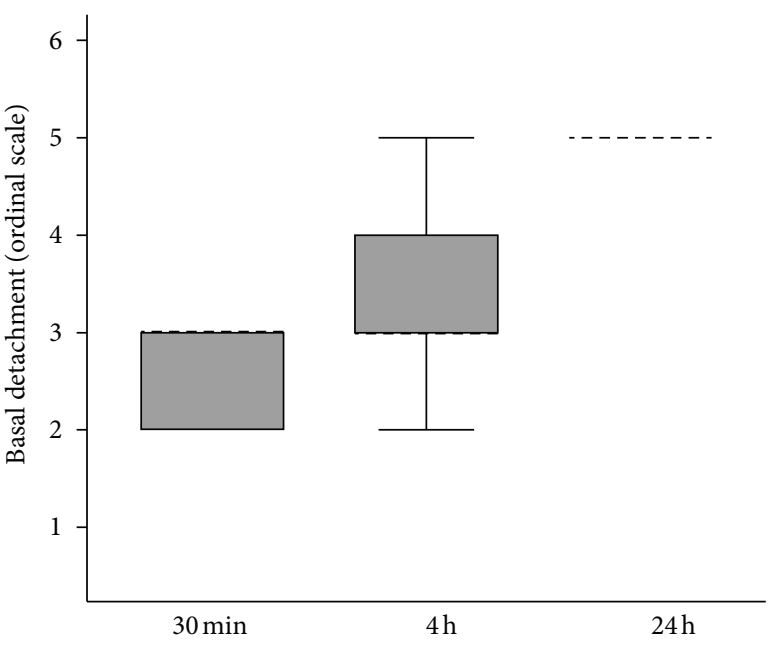

(a)

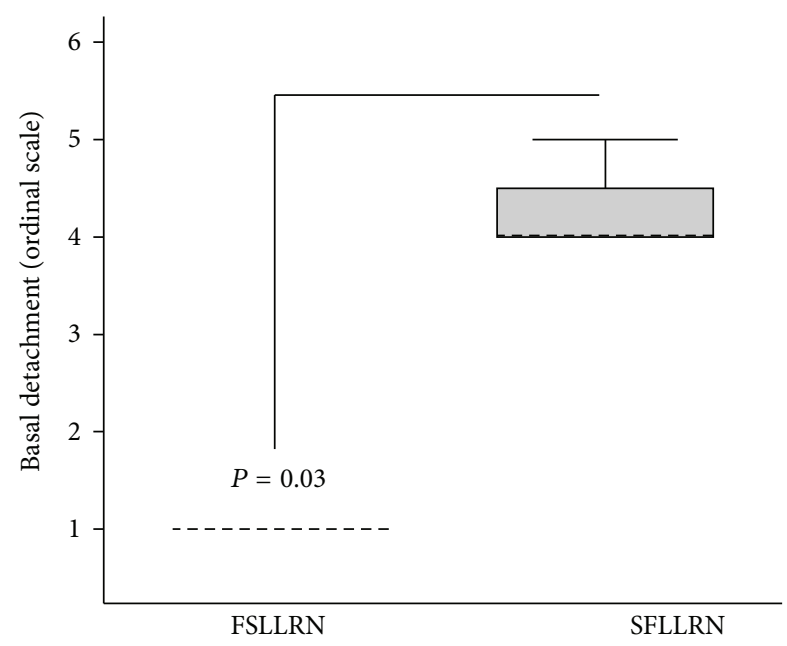

(b)

FIGURE 4: Effect of plasmin or PAR1 agonist peptide on glial cell detachment. (a) A172 cells were stimulated with plasmin (5 U/mL) for the length of time indicated, and cell detachment was quantified as defined in the Materials and Methods. (b) Effect of PAR1 specific activating peptide SFLLRN or inactive control peptide FSLLRN (both $25 \mu \mathrm{moles} / \mathrm{L}$ ) on cell detachment at 24 hours. Results were expressed as the median \pm interquartile range (IQR) from $n=4$ experiments.

by determining the area under the histogram greater than background staining in resting cells. Serum starvation was used as a positive control for apoptosis.

2.6. Statistics. Relative flourescent intensity and the morphological change scale were summarised using robust measures: median and interquartile range. Group differences were plotted using boxplots and assessed formally using the WilcoxonMann-Whitney test for two-group comparisons. Statistical analyses used exact algorithms performed in Stata 10 (Stata Corp., College Station, TX).

\section{Results}

3.1. PAR1 Receptor Cleavage Induced by Plasmin. Initial experiments examined whether PAR1 was expressed on resting A172 glioma cells. A representative flow cytometric histogram illustrates expression of PAR1 detected with a panreceptor antibody WEDE15 (Figure 1). WEDE15 staining from pooled samples $(n=8)$ demonstrated expression at an intensity of $2.31 \pm 0.33$ (median \pm interquartile range (IQR)) relative fluorescent intensity units (RFI units) at the cell surface. Proteolytic activation of PAR1 due to plasmin was monitored using a different antibody, SPAN12, specific to only the intact (i.e., unactivated) receptor (Figures 1 and 2). This antibody was expressed at a fluorescent intensity of $1.69 \pm 0.05$ RFI units (median \pm IQR.) on resting cells $(n=8)$. Activation with a purified plasmin preparation caused a statistically significant loss of SPAN12 expression at 5 minutes $(1.69 \pm 0.07$ resting cells versus $1.43 \pm 0.20$ plasmin activated; $P=0.02$; Figure 2(a)). To demonstrate whether this was due to proteolytic cleavage of the receptor by plasmin, experiments were repeated in the presence of the serine protease inhibitor aprotinin: this showed complete restoration of SPAN12 expression $(1.65 \pm 0.08 ; P=0.02$ versus plasmin alone). Analogous results were obtained when plasmin was generated in situ from plasminogen (Figure 2(b)).

3.2. Morphological Changes Induced by Plasmin. A timecourse of photomicrographs taken at 30 minutes, 4 hours and 24 hours after plasmin activation illustrates remarkable morphological transformation of A172 glioma cells (Figures 3 and $4(\mathrm{a})$ ). At 30 minutes cell processes could be observed retracting from the basal substratum, and flap formation was seen at the edges of cell lawns (Figure 3(b)). By 4 hours the cell lawn had completely detached from the well into a floating island, apparently preserving cell-to-cell contacts (Figure 3(c)). Video microscopy showing cell detachment in real time illustrated the release of individual tethers from the end of cell processes (http://youtube/FkSUdWKfoxE). The morphological changes were abrogated by $200 \mathrm{KIU} / \mathrm{mL}$ aprotinin, indicating they were dependent on serine proteolytic activity of plasmin (Figure 3(e)). To demonstrate a specific role for PAR1 in this process, a PAR1 specific activating peptide SFLLRN ( $25 \mu$ moles/L) was examined. This revealed exactly analagous morphological changes triggered through SFLLRN, but not through an inert scramble peptide FSLLRN even when used at high concentrations up to $250 \mu \mathrm{moles} / \mathrm{L}$ (Figures 3(f) and 4(b)). Morphological changes up to 4 hours following plasmin treatment were not accompanied by any detectable apoptosis as assessed with Annexin V staining by flow cytometry (Figure 5). However, at 24 hours the floating mass of glial cells had a shrivelled appearance (Figure 3(d)) and flow cytometric analysis indicated $22 \%$ of cells were apoptotic (Figure 5).

3.3. Effect of Antifibrinolytics. The effect of antifibrinolytics on glial cell morphology was determined in cultures in which plasmin was generated in situ from plasminogen. 


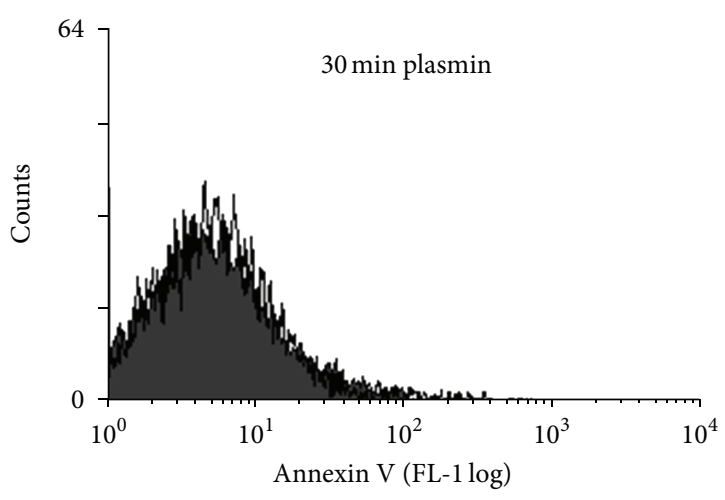

(a)

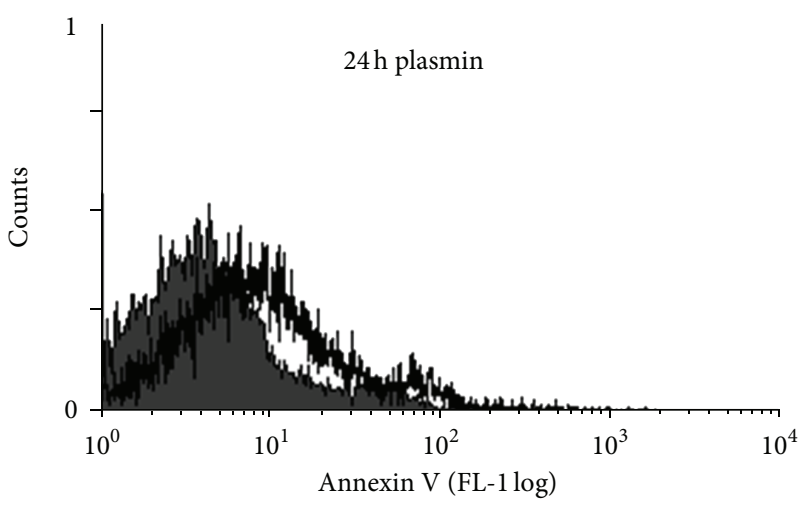

(c)

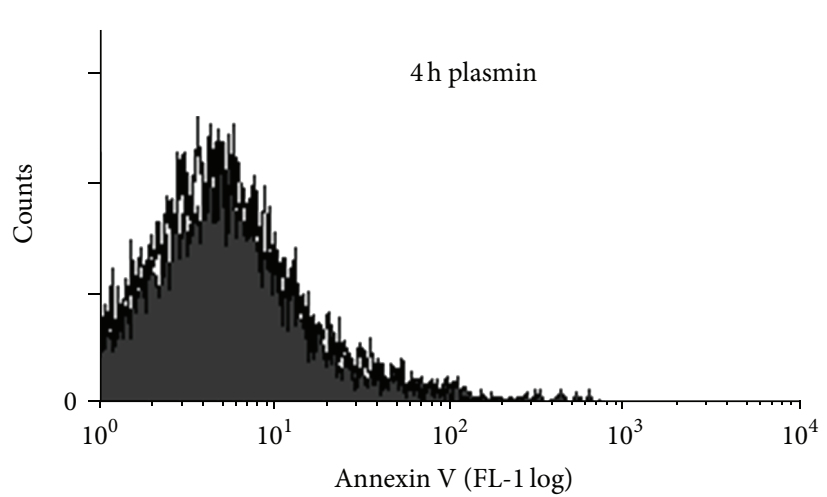

(b)

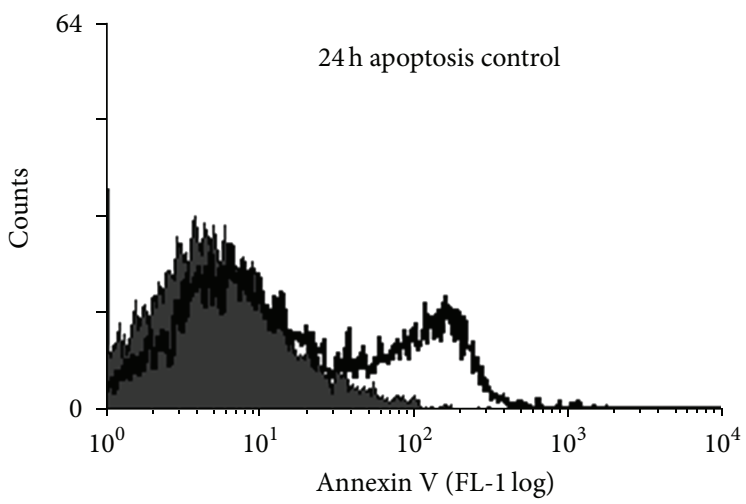

(d)

Figure 5: Effect of plasmin on glial cell apoptosis. A172 cells were stimulated with plasmin $(5 \mathrm{U} / \mathrm{mL})$ for the length of time indicated and monitored flow cytometrically for apoptosis (programmed cell death) by staining with Annexin V. Representative flow cytometric histograms depict the effect of plasmin (open histogram) versus resting cells (filled histogram) on Annexin V expression. Serum starvation was used as a positive control for apoptosis.

The antiplasmin(ogen) agents aprotinin $(200 \mathrm{KIU} / \mathrm{mL})$ and $\mathcal{E}$-aminocaproic acid $(10 \mathrm{mmoles} / \mathrm{L})$, used at concentrations equivalent to their clinical usage, statistically significantly inhibited glial cell detachment due to plasmin (each $P=$ 0.03 ; Figure 6). Biochemical assays for plasmin activity in cell cultures confirmed that each of the antifibrinolytics had abrogated plasmin activity at the concentrations employed (data not shown).

\section{Discussion}

The present study has proven the principle that plasmin can activate human glial cells via proteolytic cleavage of PAR1. The type of cell-lawn detachment observed was similar to that previously described in A172 cells treated with an integrin antagonist, that also caused separation from basal substratum and accumulation of cells into floating spheroids [31]. Although immediate cytotoxicity due to plasmin was ruled out in apoptosis assays, gradual expression of annexin $\mathrm{V}$ occurred in our culture system after 24 hours following plasmin activation. The fact that SFLLRN (but not the inactive scramble peptide FSLLRN) could recapitulate the morphological changes in A172 cells proved the role of PAR1 in this process.

These findings add to a growing literature that morphological transformation of astroglial cells can take place in a pathway involving the plasminogen activating system and components of the focal cell adhesion machinery [15, $31,32]$. An important recent study showed that tPA was capable of eliciting morphological changes and increased BBB permeability in mouse astroglial cells, through alterations to the Rho kinase (ROCK) pathway regulating focal adhesion contacts with extracellular matrix proteins [15]. A two-receptor mechanism was postulated in that study, one of which remained unknown. The unknown receptor was a receptor for plasminogen, as shown by antagonism with the antifibrinolytic agents aprotinin or tranexamic acid. The plasmin/PAR1 axis described by us was similarly antagonized by aprotinin or a lysine analog and may therefore present a plausible alternative receptor pathway.

Most studies investigating the effect of serine proteases on neuronal PAR1 have focused on thrombin, which can either be neuroprotective or, conversely, induce apoptosis in neurons, depending on concentration and length of exposure to thrombin $[7,24,25,28,33]$. Initial studies using our 


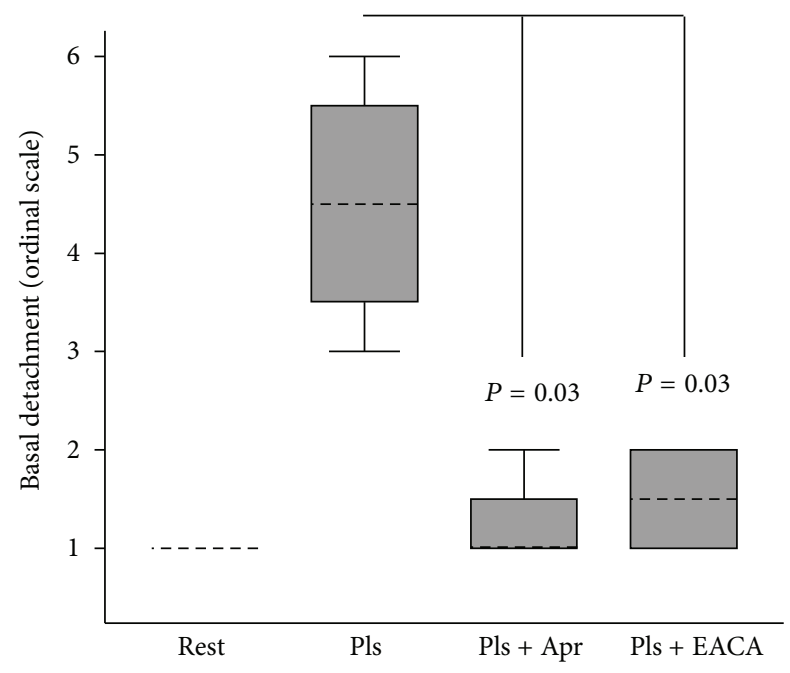

FIGURE 6: Effect of antifibrinolytics on plasmin induced glial cell detachment. A172 cells were stimulated with plasmin generated in situ from plasminogen $(5 \mathrm{U} / \mathrm{mL})$ and streptokinase $(50 \mathrm{KU} / \mathrm{mL})$ in the presence of aprotinin or $\varepsilon$-aminocaproic acid. Cell detachment was expressed in arbitrary units defined in Section 2. Results were expressed as the median \pm interquartile range (IQR) from $n=$ 4 experiments. Rest $=$ Resting; Pls $=$ plasmin; Apr $=$ aprotinin $(200 \mathrm{KIU} / \mathrm{mL}) ; \mathrm{EACA}=\varepsilon$-aminocaproic acid $(10 \mathrm{mmoles} / \mathrm{L})$.

culture system indicated that alpha-thrombin did not activate PAR1 on A172 glial cells within a physiological concentration range, but that plasmin activated PAR1 efficiently [34]. The plasmin/PAR1 axis of glial activation identified here may synergise to cause neurodegeneration with pathways of excitotoxic potentiation of $\mathrm{N}$-methyl $\mathrm{D}$-aspartate responses in neurons, also mediated via PAR1 activation with plasmin or thrombin $[27,35]$.

Cell lawn detachment may represent a manifestation of natural morphological processes, such as cell migration or astrocyte stellation. Reversal of the stellate phenotype by thrombin or changes in astrocyte morphology described for tPA may utilize the same cellular pathway, since both are regulated by ROCK $[15,36]$. Local restructuring of focal adhesion contacts and cell detachment may emulate important physiological functions linked to cell migration, wound healing, proliferation, glial scarring, and neurite formation $[17,37-40]$. Video microscopy of the cell detachment process appeared to indicate the release of individual pseudopod tethers, similar to what had been described for release or thinning of astrocyte cell processes induced by thrombin agonist $[38,41]$.

The morphological changes described here may be most relevant in the setting of neurotrauma or neuroinjury secondary to BBB breakdown, when zymogens such as plasmin that are normally confined to the systemic circulation can enter the brain [42]. A common surgical insult that compromises BBB function is cardiopulmonary bypass: this is linked to changes in glial cell morphology, neurocognitive deficits and stroke $[18,43-46]$. The demonstration that glial cells are activated via plasmin/PAR1 expands our understanding of neurodegenerative mechanisms and focuses attention on PAR1 as a possible drug target for neuroprotection. While PAR1 deficient mice are protected in various models of ischemia, it is simplistic to consider PAR1 antagonism as a treatment option to block astroglial pathways of neuroinjury, since a clinical trial with the oral PAR1 antagonist vorapaxar for treatment of acute coronary syndromes was associated with significantly higher rates of intracerebral hemorrhage $[22,47,48]$. A desirable outcome would be to combine thrombolytic properties without hemorrhage or compromise of $\mathrm{BBB}$ permeability; however, this outcome remains elusive. However, plasmin inhibitors are neuroprotective, and the plasmin/PAR1 axis identified here may be explored further as a therapeutic target $[17,49-51]$.

There are some limitations to this study. The cell culture system may fail adequately to model the homeostatic environment of the brain, which is endowed not only with serine proteases and their zymogens but also naturally occurring serine protease inhibitors (serpins) [52, 53]. Furthermore, the in vitro cell culture model may not faithfully replicate in vivo pathways of glial injury caused by plasmin nor the three-dimensional cell-cell and cell-substrate interaction that arises from the precise cellular organization that exists within the brain. However, a reductionist cell culture approach as employed here is well suited to prove unequivocally that glial cells can be activated through proteolytic cleavage of PAR1 due to plasmin.

In conclusion, we have identified a PAR1 axis of glial cell activation triggered by plasmin or the plasminogen system. This may be especially relevant under conditions of $\mathrm{BBB}$ breakdown or intracranial hemorrhage when serine proteases gain access to the neurovascular unit.

\section{Acknowledgments}

R. C. Landis discloses unrestricted research grants from the Barbados Diabetes Foundation and Bayer Pharmaceuticals Inc. which supported this work. The authors declare that they have no conflict of interests.

\section{References}

[1] I. Clemmensen and R. B. Andersen, "The fibrinolytic system and its relation to inflammatory diseases," Seminars in Arthritis and Rheumatism, vol. 11, no. 4, pp. 390-398, 1982.

[2] N. Kamio, H. Hashizume, S. Nakao, K. Matsushima, and H. Sugiya, "Plasmin is involved in inflammation via proteaseactivated receptor-1 activation in human dental pulp," Biochemical Pharmacology, vol. 75, no. 10, pp. 1974-1980, 2008.

[3] T. M. Quinton, S. Kim, C. K. Derian, J. Jin, and S. P. Kunapuli, "Plasmin-mediated activation of platelets occurs by cleavage of protease-activated receptor 4," The Journal of Biological Chemistry, vol. 279, no. 18, pp. 18434-18439, 2004.

[4] V. Lukic-Panin, K. Deguchi, T. Yamashita et al., "Free radical scavenger edaravone administration protects against tissue plasminogen activator induced oxidative stress and blood brain barrier damage," Current Neurovascular Research, vol. 7, no. 4, pp. 319-329, 2010. 
[5] S. L. Raza, L. C. Nehring, S. D. Shapiro, and L. A. Cornelius, "Proteinase-activated receptor-1 regulation of macrophage elastase (MMP-12) secretion by serine proteinases," The Journal of Biological Chemistry, vol. 275, no. 52, pp. 41243-41250, 2000.

[6] S. C. Even-Ram, M. Maoz, E. Pokroy et al., "Tumor cell invasion is promoted by activation of protease activated receptor- 1 in cooperation with the alpha vbeta 5 integrin," The Journal of Biological Chemistry, vol. 276, no. 14, pp. 10952-10962, 2001.

[7] E. Sokolova and G. Reiser, "Prothrombin/thrombin and the thrombin receptors PAR- 1 and PAR-4 in the brain: localization, expression and participation in neurodegenerative diseases," Thrombosis and Haemostasis, vol. 100, no. 4, pp. 576-581, 2008.

[8] V. J. Marder, "Historical perspective and future direction of thrombolysis research: the re-discovery of plasmin," Journal of Thrombosis and Haemostasis, vol. 9, no. 1, pp. 364-373, 2011.

[9] F. Olldashi, M. Kerçi, T. Zhurda et al., "The importance of early treatment with tranexamic acid in bleeding trauma patients: an exploratory analysis of the CRASH-2 randomised controlled trial," The Lancet, vol. 377, no. 9771, pp. 1096-1101, 1101.e11101.e2, 2011.

[10] D. A. Henry, A. J. Moxey, P. A. Carless et al., "Anti-fibrinolytic use for minimising perioperative allogeneic blood transfusion," Cochrane Database of Systematic Reviews, no. 1, Article ID CD001886, 2001.

[11] S. Fujimoto, H. Katsuki, M. Ohnishi, M. Takagi, T. Kume, and A. Akaike, "Plasminogen potentiates thrombin cytotoxicity and contributes to pathology of intracerebral hemorrhage in rats," Journal of Cerebral Blood Flow and Metabolism, vol. 28, no. 3, pp. 506-515, 2008.

[12] J. J. Sheehan, C. Zhou, I. Gravanis et al., "Proteolytic activation of monocyte chemoattractant protein- 1 by plasmin underlies excitotoxic neurodegeneration in mice," Journal of Neuroscience, vol. 27, no. 7, pp. 1738-1745, 2007.

[13] S. E. Tsirka, T. H. Bugge, J. L. Degen, and S. Strickland, "Neuronal death in the central nervous system demonstrates a non-fibrin substrate for plasmin," Proceedings of the National Academy of Sciences of the United States of America, vol. 94, no. 18, pp. 9779-9781, 1997.

[14] S. E. Tsirka, A. D. Rogove, T. H. Bugge, J. L. Degen, and S. Strickland, "An extracellular proteolytic cascade promotes neuronal degeneration in the mouse hippocampus," Journal of Neuroscience, vol. 17, no. 2, pp. 543-552, 1997.

[15] B. Niego, R. Freeman, T. B. Puschmann, A. M. Turnley, and R. L. Medcalf, "t-PA-specific modulation of a human bloodbrain barrier model involves plasmin-mediated activation of the Rho kinase pathway in astrocytes," Blood, vol. 119, no. 20, pp. 4752-4761, 2012.

[16] Y. F. Wang, S. E. Tsirka, S. Strickland, P. E. Stieg, S. G. Soriano, and S. A. Lipton, "Tissue plasminogen activator (tPA) increases neuronal damage after focal cerebral ischemia in wild-type and tPA-deficient mice," Nature Medicine, vol. 4, no. 2, pp. 228-231, 1998.

[17] F. Adhami, D. Yu, W. Yin et al., "Deleterious effects of plasminogen activators in neonatal cerebral hypoxia-ischemia," American Journal of Pathology, vol. 172, no. 6, pp. 1704-1716, 2008.

[18] B. Reinsfelt, S.-E. Ricksten, H. Zetterberg, K. Blennow, J. Fredén-Lindqvist, and A. Westerlind, "Cerebrospinal fluid markers of brain injury, inflammation, and blood-brain barrier dysfunction in cardiac surgery," Annals of Thoracic Surgery, vol. 94, no. 2, pp. 549-555, 2012.
[19] T. K. H. Vu, V. I. Wheaton, D. T. Hung, I. Charo, and S. R. Coughlin, "Domains specifying thrombin-receptor interaction," Nature, vol. 353, no. 6345, pp. 674-677, 1991.

[20] T. K. H. Vu, D. T. Hung, V. I. Wheaton, and S. R. Coughlin, "Molecular cloning of a functional thrombin receptor reveals a novel proteolytic mechanism of receptor activation," Cell, vol. 64, no. 6, pp. 1057-1068, 1991.

[21] M. Poullis, R. Manning, M. Laffan, D. O. Haskard, K. M. Taylor, and R. C. Landis, "The antithrombotic effect of aprotinin: actions mediated via the protease-activated receptor 1,"Journal of Thoracic and Cardiovascular Surgery, vol. 120, no. 2, pp. 370-378, 2000.

[22] C. E. Junge, T. Sugawara, G. Mannaioni et al., "The contribution of protease-activated receptor 1 to neuronal damage caused by transient focal cerebral ischemia," Proceedings of the National Academy of Sciences of the United States of America, vol. 100, no. 22, pp. 13019-13024, 2003.

[23] E. E. Olson, P. Lyuboslavsky, S. F. Traynelis, and R. J. McKeon, "PAR-1 deficiency protects against neuronal damage and neurologic deficits after unilateral cerebral hypoxia/ischemia," Journal of Cerebral Blood Flow and Metabolism, vol. 24, no. 9, pp. 964-971, 2004.

[24] Y. Wang, W. Luo, and G. Reiser, "Activation of proteaseactivated receptors in astrocytes evokes a novel neuroprotective pathway through release of chemokines of the growth-regulated oncogene/cytokine-induced neutrophil chemoattractant family," European Journal of Neuroscience, vol. 26, no. 11, pp. 3159-3168, 2007.

[25] F. M. Donovan and D. D. Cunningham, "Signaling pathways involved in thrombin-induced cell protection," The Journal of Biological Chemistry, vol. 273, no. 21, pp. 12746-12752, 1998.

[26] M. B. Gingrich, C. E. Junge, P. Lyuboslavsky, and S. F. Traynelis, "Potentiation of NMDA receptor function by the serine protease thrombin," Journal of Neuroscience, vol. 20, no. 12, pp. 4582-4595, 2000.

[27] G. Mannaioni, A. G. Orr, C. E. Hamill et al., "Plasmin potentiates synaptic $\mathrm{N}$-methyl-D-aspartate receptor function in hippocampal neurons through activation of protease-activated receptor-1," The Journal of Biological Chemistry, vol. 283, no. 29, pp. 20600-20611, 2008.

[28] L. J. Houenou, “Thrombin perturbs neurite outgrowth and induces apoptotic cell death in enriched chick spinal motoneuron cultures through caspase activation," Journal of Neuroscience, vol. 18, no. 17, pp. 6882-6891, 1998.

[29] J. R. S. Day, K. M. Taylor, E. A. Lidington et al., "Aprotinin inhibits proinflammatory activation of endothelial cells by thrombin through the protease-activated receptor 1," Journal of Thoracic and Cardiovascular Surgery, vol. 131, no. 1, pp. 21-27, 2006.

[30] L. F. Brass, S. Pizarro, M. Ahuja et al., "Changes in the structure and function of the human thrombin receptor during receptor activation, internalization, and recycling," The Journal of Biological Chemistry, vol. 269, no. 4, pp. 2943-2952, 1994.

[31] A. Maglott, P. Bartik, S. Cosgun et al., “The small $\alpha 5 \beta 1$ integrin antagonist, SJ749, reduces proliferation and clonogenicity of human astrocytoma cells," Cancer Research, vol. 66, no. 12, pp. 6002-6007, 2006.

[32] Y. Fukushima, M. Tamura, H. Nakagawa, and K. Itoh, "Induction of glioma cell migration by vitronectin in human serum and cerebrospinal fluid," Journal of Neurosurgery, vol. 107, no. 3, pp. 578-585, 2007. 
[33] Z. Suo, B. A. Citron, and B. W. Festoff, "Thrombin: a potential proinflammatory mediator in neurotrauma and neurodegenerative disorders," Current Drug Targets, vol. 3, no. 1, pp. 105-114, 2004.

[34] R. C. Landis and K. D. Hall, "Plasmin but not thrombin activates A172 glial cells via serine proteolytic cleavage of preoteaseactivated receptor (PAR)1," Heart Surgery Forum, vol. 11, no. 5, article 278, 2008.

[35] C. E. Hamill, G. Mannaioni, P. Lyuboslavsky, A. A. Sastre, and S. F. Traynelis, "Protease-activated receptor 1-dependent neuronal damage involves NMDA receptor function," Experimental Neurology, vol. 217, no. 1, pp. 136-146, 2009.

[36] H. S. Suidan, C. D. Nobes, A. Hall, and D. Monard, "Astrocyte spreading in response to thrombin and lysophosphatidic acid is dependent on the Rho GTPase," GLIA, vol. 21, no. 2, pp. 244-252, 1997.

[37] O. Nicole, A. Goldshmidt, C. E. Hamill et al., "Activation of protease-activated receptor-1 triggers astrogliosis after brain injury," Journal of Neuroscience, vol. 25, no. 17, pp. 4319-4329, 2005.

[38] K. P. Cavanaugh, D. Gurwitz, D. D. Cunningham, and R. A. Bradshaw, "Reciprocal modulation of astrocyte stellation by thrombin and protease nexin-1," Journal of Neurochemistry, vol. 54, no. 5, pp. 1735-1743, 1990.

[39] D. D. Cunningham and D. Gurwitz, "Proteolytic regulation of neurite outgrowth from neuroblastoma cells by thrombin and protease nexin-1," Journal of Cellular Biochemistry, vol. 39, no. 1, pp. 55-64, 1989.

[40] S. F. Traynelis and J. Trejo, "Protease-activated receptor signaling: new roles and regulatory mechanisms," Current Opinion in Hematology, vol. 14, no. 3, pp. 230-235, 2007.

[41] T. Okamoto, M. Nishibori, K. Sawada et al., "The effects of stimulating protease-activated receptor- 1 and -2 in A172 human glioblastoma," Journal of Neural Transmission, vol. 108, no. 2, pp. 125-140, 2001.

[42] M. B. Gingrich and S. F. Traynelis, "Serine proteases and brain damage-is there a link?" Trends in Neurosciences, vol. 23, no. 9, pp. 399-407, 2000.

[43] C. Landis, "Why the inflammatory response is important to the cardiac surgical patient," Journal of Extra-Corporeal Technology, vol. 39, no. 4, pp. 281-284, 2007.

[44] D. A. Stump, "Deformable emboli and inflammation: temporary or permanent damage?" Journal of Extra-Corporeal Technology, vol. 39, no. 4, pp. 289-290, 2007.

[45] A. M. Schuller, J. Windolf, R. Blaheta et al., "Degradation of microvascular brain endothelial cell $\beta$-catenin after co-culture with activated neutrophils from patients undergoing cardiac surgery with prolonged cardiopulmonary bypass," Biochemical and Biophysical Research Communications, vol. 329, no. 2, pp. 616-623, 2005.

[46] M. Scholz, J. Cinatl, M. Schädel-Höpfner, and J. Windolf, "Neutrophils and the blood-brain barrier dysfunction after trauma," Medicinal Research Reviews, vol. 27, no. 3, pp. 401-416, 2007.

[47] P. Tricoci, Z. Huang, C. Held et al., “Thrombin-receptor antagonist vorapaxar in acute coronary syndromes," The New England Journal of Medicine, vol. 366, no. 1, pp. 20-33, 2012.

[48] C. E. Junge, C. J. Lee, K. B. Hubbard et al., "Protease-activated receptor-1 in human brain: localization and functional expression in astrocytes," Experimental Neurology, vol. 188, no. 1, pp. 94-103, 2004.
[49] O. Eser, E. Kalkan, M. Cosar et al., “The effect of aprotinin on brain ischemic-reperfusion injury after hemorrhagic shock in rats: an experimental study," Journal of Trauma, vol. 63, no. 2, pp. 373-378, 2007.

[50] K. Durgut, K. Hosgor, N. Gormus, U. Ozergin, and H. Solak, "The cerebroprotective effects of pentoxifylline and aprotinin during cardiopulmonary bypass in dogs," Perfusion, vol. 19, no. 2, pp. 101-106, 2004.

[51] V. Anttila, I. Hagino, Y. Iwata et al., "Aprotinin improves cerebral protection: evidence from a survival porcine model," Journal of Thoracic and Cardiovascular Surgery, vol. 132, no. 4, pp. 948-953, 2006.

[52] V. L. Turgeon and L. J. Houenou, “The role of thrombin-like (serine) proteases in the development, plasticity and pathology of the nervous system," Brain Research Reviews, vol. 25, no. 1, pp. 85-95, 1997.

[53] P. Rossignol, B. Ho-Tin-Noé, R. Vranckx et al., "Protease nexin-1 inhibits plasminogen activation-induced apoptosis of adherent cells," The Journal of Biological Chemistry, vol. 279, no. 11, pp. 10346-10356, 2004. 


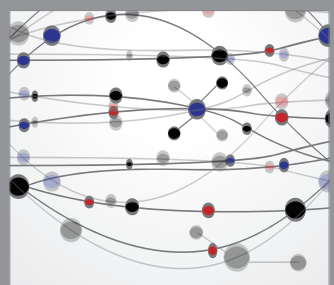

The Scientific World Journal
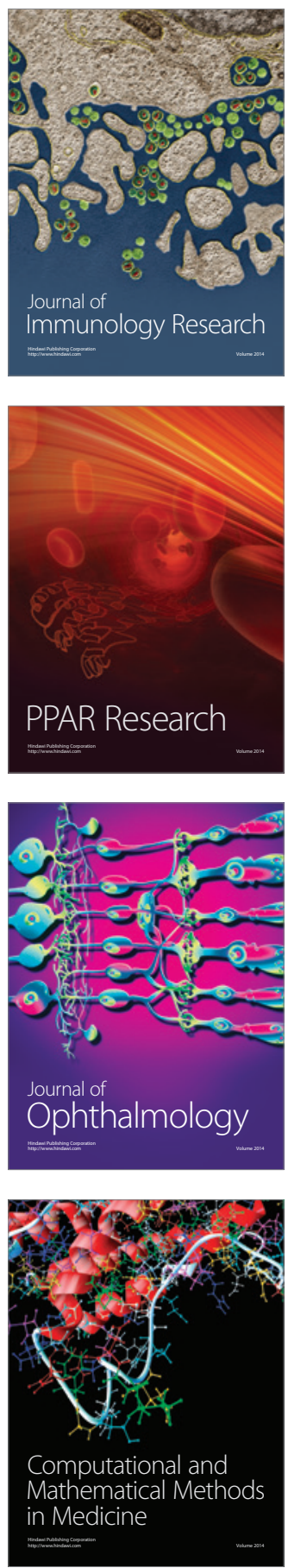

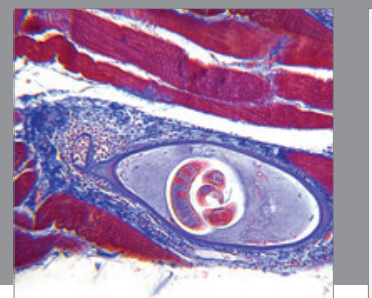

Gastroenterology

Research and Practice
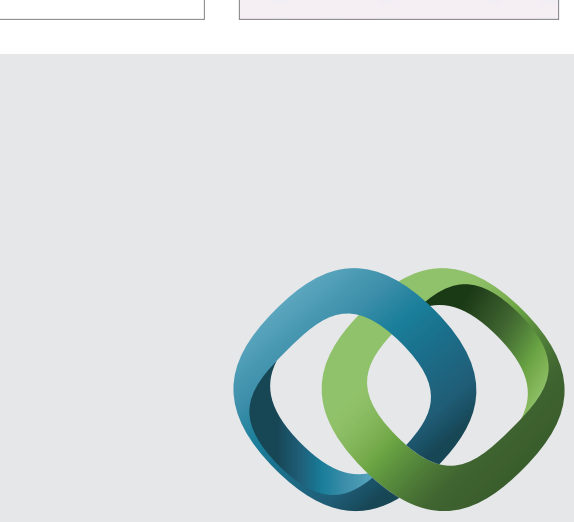

\section{Hindawi}

Submit your manuscripts at

http://www.hindawi.com
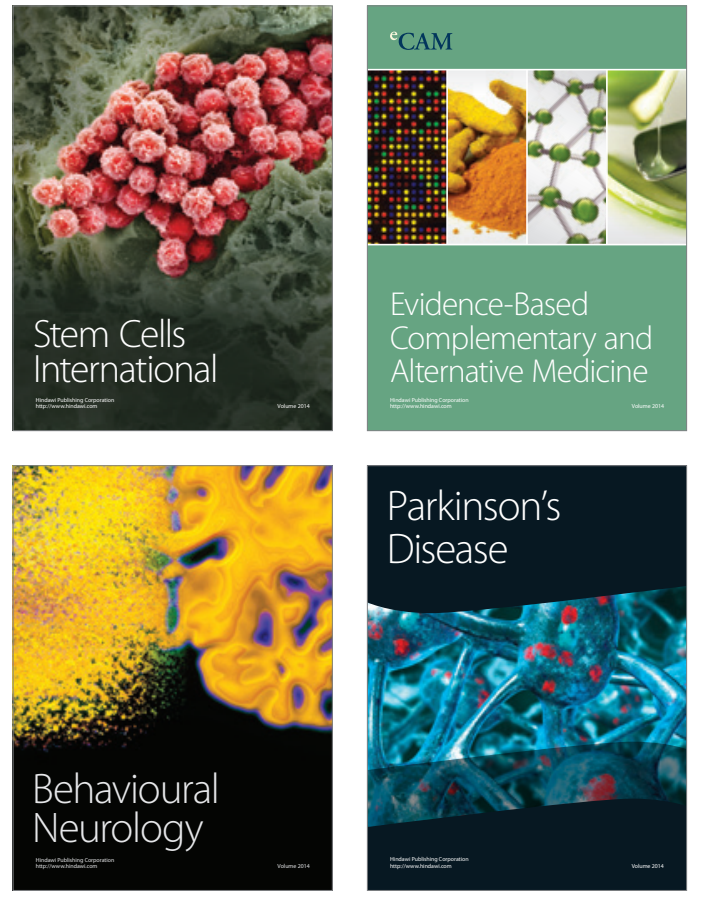
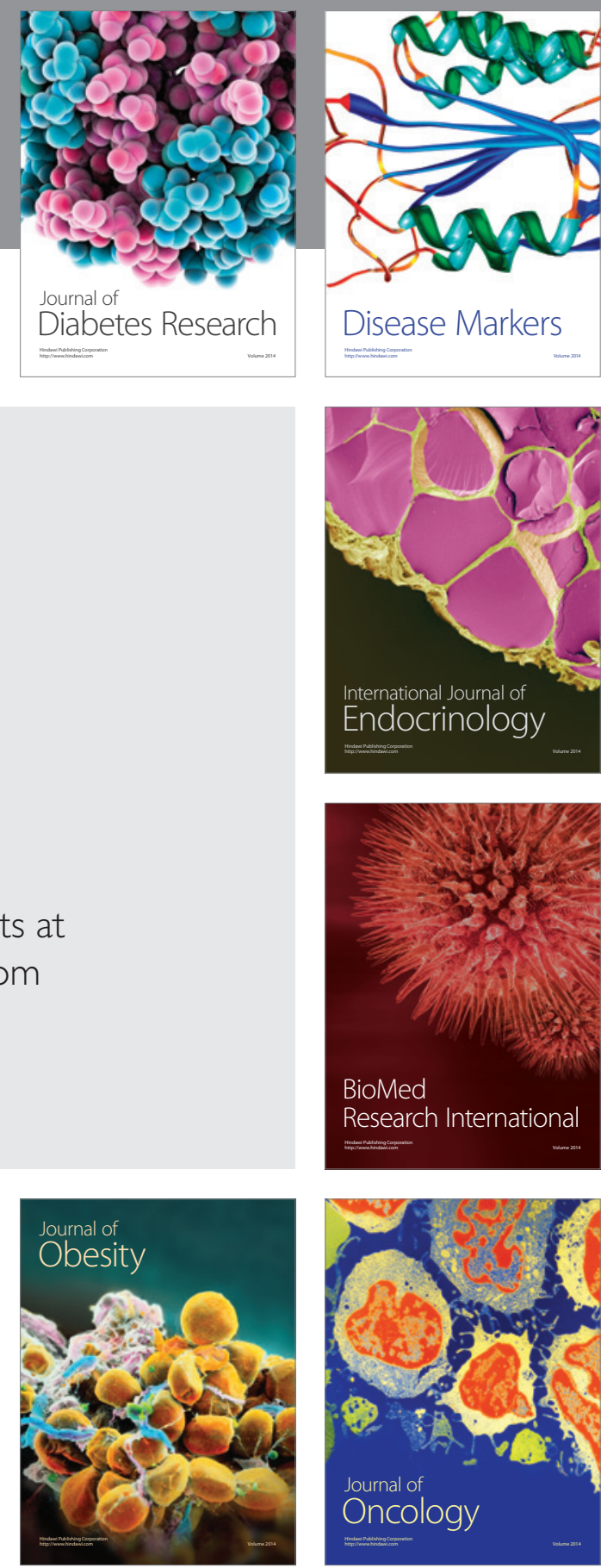

Disease Markers
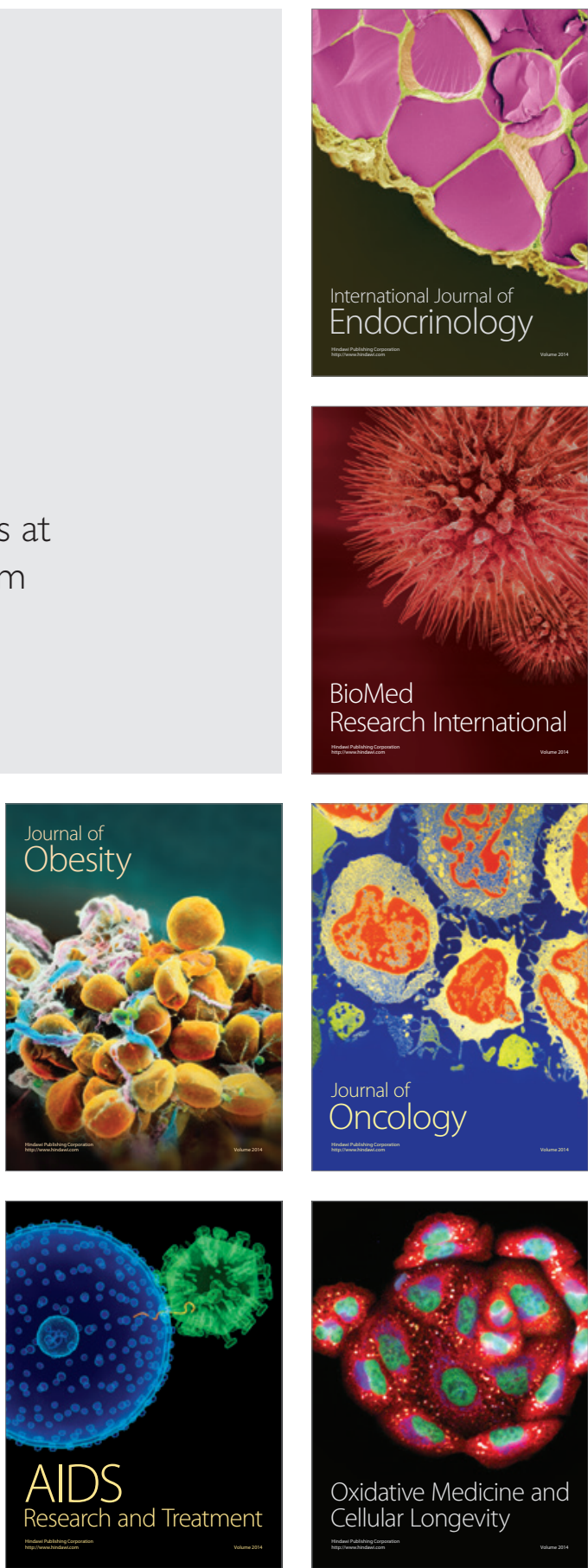